\title{
INVESTIGATING POSSIBILITIES OF CRACK INITIATION LIFE EXTENSION IN JET ENGINES COMPRESSOR DISKS
}

\author{
Strain Posavljak ${ }^{1}$, Gordana Tosic ${ }^{2}$, Katarina Maksimovic ${ }^{3}$ \\ ${ }^{1}$ University of Banja Luka, Faculty of Mechanical Engineering, 71 Vojvode Stepe Stepanovica \\ Street, 78000 Banja Luka, Republic of Srpska, Bosnia and Herzegovina \\ E-mail: strain.posavljak@mf.unibl.org \\ ${ }^{2}$ University of Banja Luka, Faculty of Mechanical Engineering, 71 Vojvode Stepe Stepanovica \\ Street, 78000 Banja Luka, Republic of Srpska, Bosnia and Herzegovina \\ E-mail: gordana.tosic@mf.unibl.org \\ ${ }^{3}$ Secretariat for Utilities and Housing Services Water Management, 1 Kraljice Marije Street, \\ Belgrade, Serbia \\ E-mail: kmaksimovic@mts.rs \\ *corresponding author
}

\begin{abstract}
This paper deals with jet engines compressor disks which have dovetail joints with blades. A compressor disk with reduced fatigue resistance was taken as an example. Two simplified conceptual solutions of the dovetail joint with blades were devised. Based on the low cycle fatigue theory, the crack initiation life of their critical parts with newly-proposed transition rounding at the bottom of dovetail grooves was estimated. Two different flank angles in the dovetail grooves $\left(60^{\circ}\right.$ in the critical part that belongs to the first dovetail joint conceptual solution and $55^{\circ}$ in the critical part that belongs to the second dovetail joint conceptual solution), two different aviation steels selected for workmanship (13H11N2V2MF and AISI 304 steel) and two load histories (load history LH1 and load history LH2), were taken into account. By load history LH2 an overload of the critical parts was simulated. The results of crack initiation life estimation of the critical parts in the dovetail joint conceptual solutions show that there is a possibility for the crack initiation life extension of the observed compressor disk. In all analyzed variants, it has been shown that the critical part in the second dovetail joint conceptual solution has longer crack initiation life than the critical part in the first dovetail joint conceptual solution. For example, the critical part in the second dovetail joint conceptual solution made of AISI 304 steel, in the case of load history LH1 has $141.55 \%$ longer crack initiation life than the critical part in the first dovetail joint conceptual solution made of $13 \mathrm{H} 11 \mathrm{~N} 2 \mathrm{~V} 2 \mathrm{MF}$ steel. In the case of load history LH2 (an overload case) that percent is greater and amounts to $173.15 \%$.
\end{abstract}

Keywords: Jet engines, compressor disks, dovetail joints, crack initiation, life extension.

\section{Introduction}

During exploitation, jet engine compressors and turbine disks are exposed to low cycle fatigue. Their service life observed as crack initiation life is limited and prescribed by jet engines 
producers. In practice, it can happen that the prescribed service life of some disks is not reached (Posavljak, 2008). The reasons for this can be different, such as poorly chosen geometry, inadequate surface quality, the disk material has bad cyclic properties, inadequate spin tests, overload in operation and, finally, the lack of exact crack initiation life assessment methods.

As a result of loads in the form of their own centrifugal forces, centrifugal forces of blades, gas-dynamic forces, plus elevated temperature, "premature" cracks can be caused in the stressed areas of disks, due to the appearance of increased elasto-plastic strains. The stressed areas of jet engine disks are rims, areas with holes of different purposes and hubs. Here, interesting rims are stressed because of joint with blades. In many cases, crack initiation life of disks is determined by the quality of these joints.

The typical joint of the compressor's disks with blades is dovetail joint, for which interest has not ceased. For example, Shlyannikov, Yarullin and Ishtyryakov (2019), Stepovoy and Pribora (2018) and Kozakiewicz, Grzejszczak and Lacki (2017) have analyzed different ways, jet engine compressor disks and their dovetail joints with blades.

\section{Case of one jet engine compressor disk and its dovetail joint with blades}

\subsection{Introductory information}

The existing first stage low pressure compressor disk of R25-300 jet engine, here observed as disk D1, has a dovetail joint with blades. The service life of 1200 flight hours of this disk, made of $13 \mathrm{H} 11 \mathrm{~N} 2 \mathrm{~V} 2 \mathrm{MF}$ steel, has never been reached because of "premature" cracks which appeared in the region of the transition rounding at the dovetail groove bottom. This fact is confirmed by Weibull's probability expression of cracks appearance that was established by Posavljak (2008), in the form:

$$
P(t)=1-e^{-\left(\frac{t}{336}\right)^{2.764}}
$$

The diagram of this probability and a sample of disk D1 with discovered crack is presented in Fig. 1.

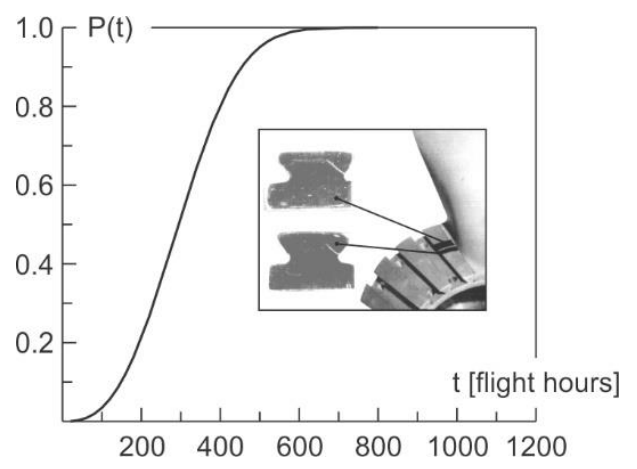

Fig. 1. Weibull's probability diagram of crack appearance and a sample of disk D1 with discovered crack

The practical crack initiation life of disk D1 for the probability 0.001 amounts to 27.6 flight hours and for the probability 0.999 it amounts to 676.1 flight hours. 
Posavljak (2008) proved that the existing transition rounding at the dovetail grooves bottom in disk D1 needs to be replaced by the new transition rounding if we want to extend the crack initiation life. New transition rounding, better than the existing, was proposed for disk D2 that represents the second version of the first stage low pressure compressor disk of R25-300 jet engine, made of $13 \mathrm{H} 11 \mathrm{~N} 2 \mathrm{~V} 2 \mathrm{MF}$ steel in the heat treatment state (heating at $1000{ }^{\circ} \mathrm{C}$, oil quenching, tempering at $640^{\circ} \mathrm{C}$ and air cooling). The existing and newly-proposed transition rounding can be seen in Fig. 2.
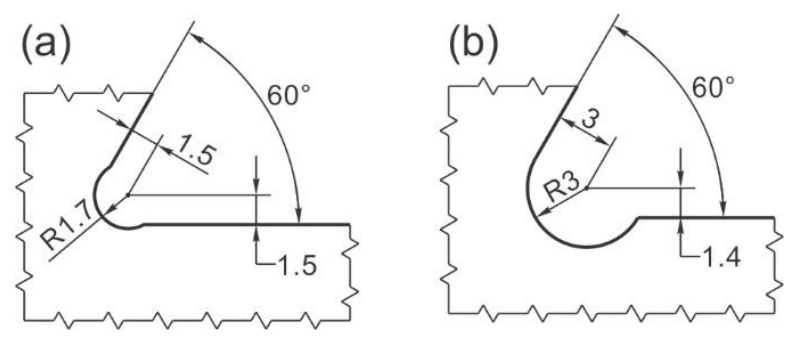

Fig. 2. Transition rounding at the dovetail groove bottom of disk D1 (a) and newly-proposed transition rounding for disk D2 (b)

Newly-proposed transition rounding shown in Fig. $2 \mathrm{~b}$ will be kept in two conceptual dovetail joint solutions that will be discussed here. The task is to discover the other possibilities of crack initiation life extension of the first stage low pressure compressor disk of R25-300 jet engine and accordingly to this, to suggest its third version marked as disk D3.

\subsection{Conceptual dovetail joint solutions}

The joints with blades of the first stage low pressure compressor disk of R25-300 jet engine, as dovetail joints, are simplified here. The first conceptual dovetail joint solution, with identified main parts (lower and upper part), is shown in Fig. 3.
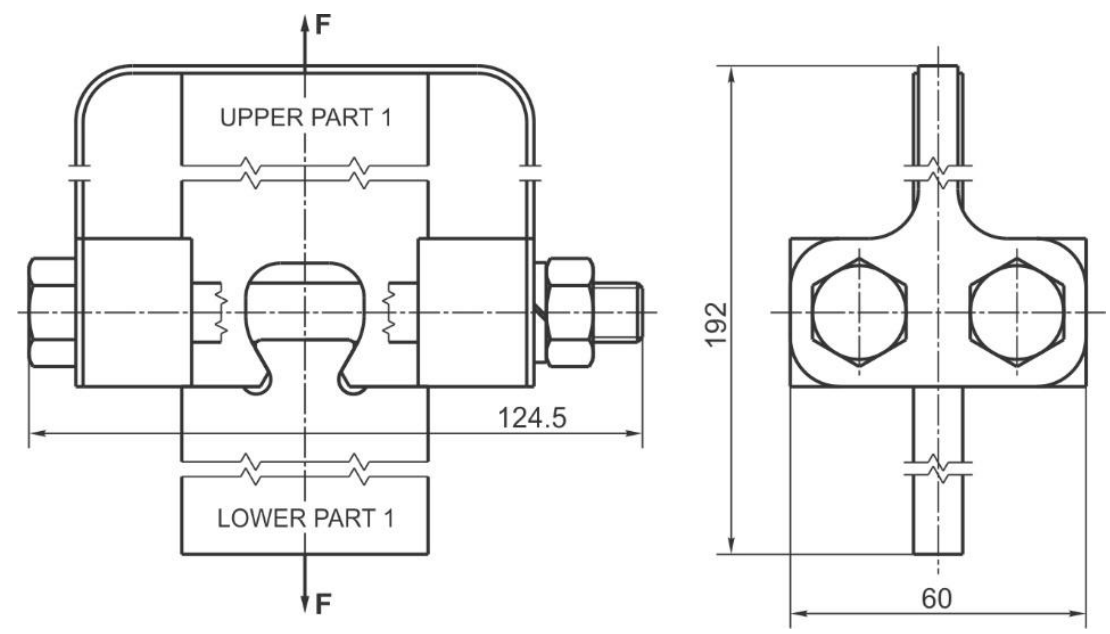

Fig. 3. The first conceptual dovetail joint solution with identified main parts (the lower and upper part) 
The second conceptual dovetail solution is not shown here, as it is similar to the first. Taking into consideration dimensionally defined lower parts LP1 and LP2 (Fig. 4) and upper parts UP1 and UP2 (Fig. 5), the difference between our two conceptual dovetail joint solutions can be noticed.
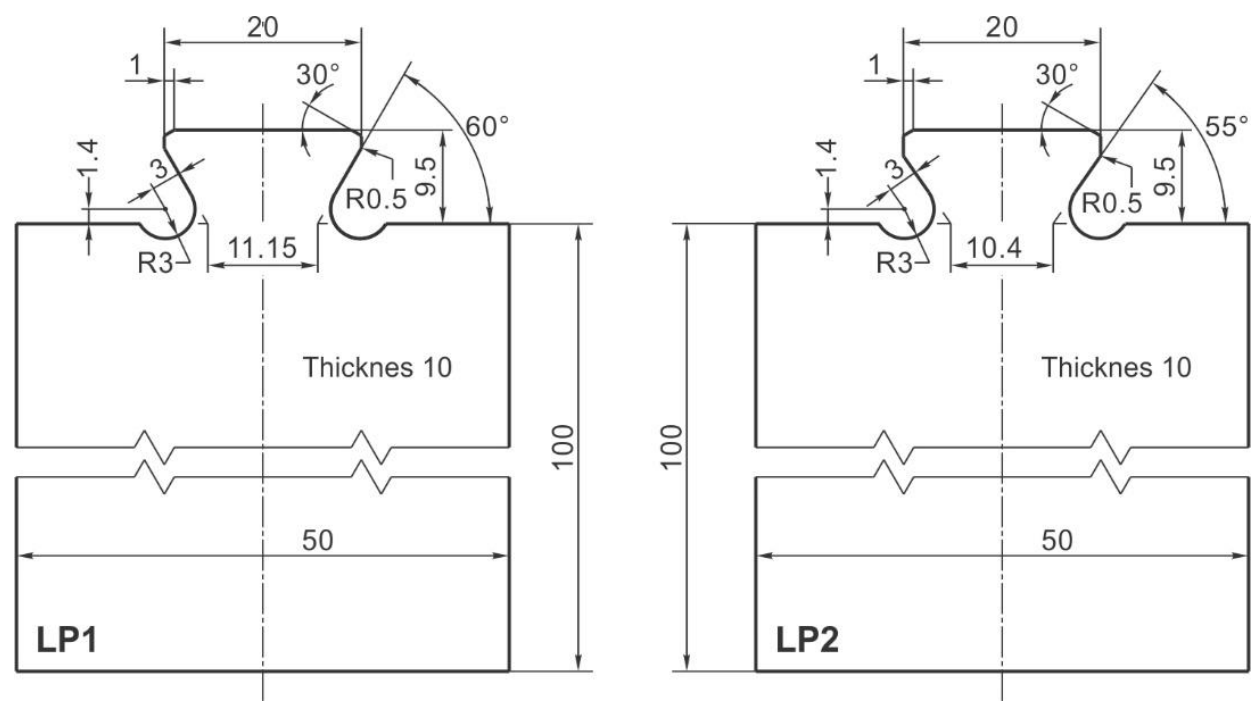

Fig. 4. The lower parts LP1 and LP2 of the first and the second conceptual dovetail joint solution
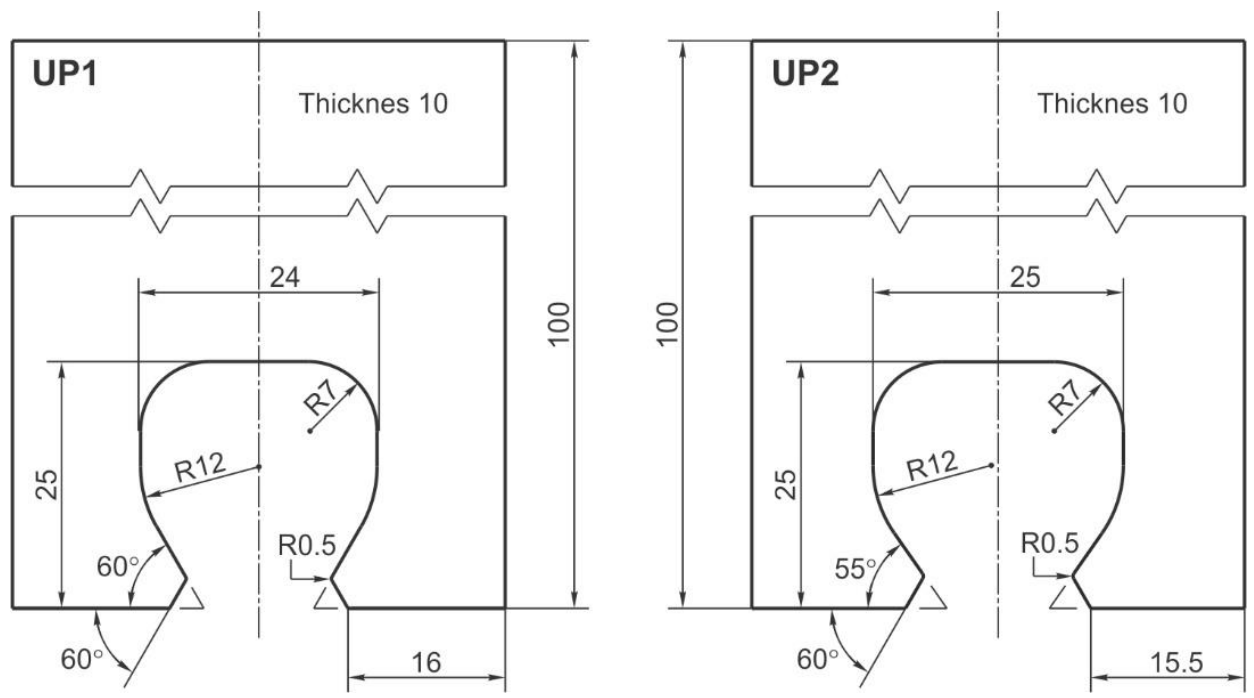

Fig. 5. The upper parts UP1 and UP2 of the first and the second conceptual dovetail joint solution 
2.3 Fatigue properties of materials selected for the main parts workmanship of dovetail joint conceptual solutions

Two aviation steels, $13 \mathrm{H} 11 \mathrm{~N} 2 \mathrm{~V} 2 \mathrm{MF}$ steel (S1 steel) in the above mentioned heat treatment state and AISI 304 steel (S2 steel), were selected for the main parts workmanship of conceptual dovetail joint solutions.

Fatigue properties of $13 \mathrm{H} 11 \mathrm{~N} 2 \mathrm{~V} 2 \mathrm{MF}$ steel, experimentally in the regime of controlled strains, obtained by Posavljak (2008) and fatigue properties of AISI 304 steel taken from SAE J1099 (2002), are presented in Table 1.

\begin{tabular}{|l|c|c|}
\hline Property & $\begin{array}{c}\text { 13H11N2V2MF steel } \\
(\mathrm{S} 1 \text { steel })\end{array}$ & $\begin{array}{c}\text { AISI 304 steel } \\
\text { (S2 steel) }\end{array}$ \\
\hline Modulus of elasticity, E [MPa] & 229184.6 & 190000 \\
\hline Cyclic strength coefficient, $\mathrm{K}^{\prime}[\mathrm{MPa}]$ & 1140 & 2275 \\
\hline Cyclic strain hardening exponent, $\mathrm{n}^{\prime}$ & 0.0579 & 0.334 \\
\hline Fatigue strength coefficient, $\sigma_{\mathrm{f}}^{\prime}[\mathrm{MPa}]$ & 1557.3 & 1267 \\
\hline Fatigue strength exponent, $\mathrm{b}$ & -0.0851 & -0.139 \\
\hline Fatigue ductility coefficient, $\varepsilon_{\mathrm{f}}^{\prime}$ & 0.3175 & 0.174 \\
\hline Fatigue ductility exponent, $\mathrm{c}$ & -0.7214 & -0.415 \\
\hline
\end{tabular}

Table 1. Fatigue properties of 13H11N2V2MF steel and AISI 304 steel

\subsection{Load histories of observed dovetail joints}

Assuming that dovetail joints would be exposed to the load histories LH1 and LH2 that shown in Fig. 6. These histories include positively variable force $F$. By the load history LH2 an overload of $10 \%$ will be simulated.

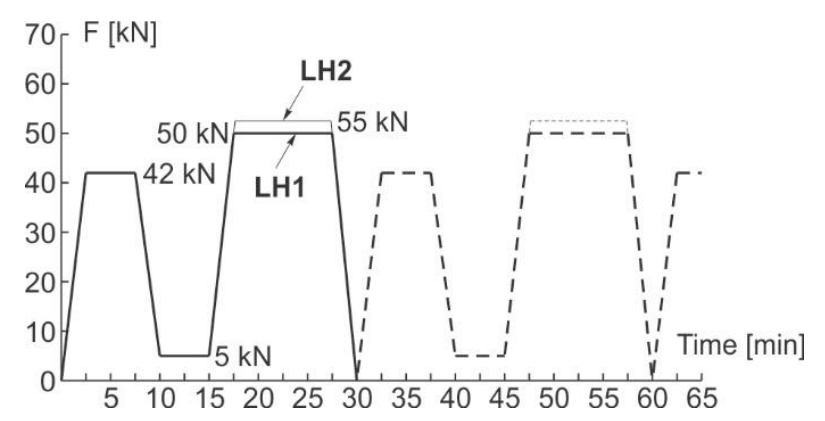

Fig. 6. Load histories LH1 and LH2

Fig. 7 shows the shortened array of simplified load history LH1. Applying the method of "reservoir", as Kostaes (2001) did, the force cycles 50-0-50 kN and 42-5-42 kN were identified in that array.

In the similar way, 55-0-55 $\mathrm{kN}$ and $42-5-42 \mathrm{kN}$ force cycles would be identified in the shortened array of simplified load histories LH2. 


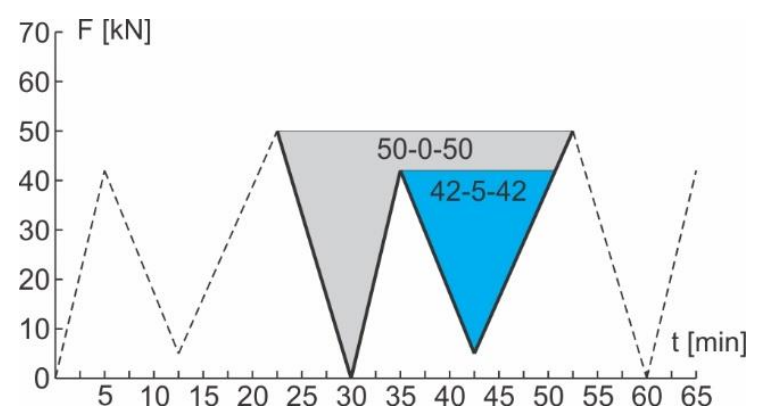

Fig. 7. The shortened array of simplified load histories LH1 with identified force cycles

\subsection{Local stress-strain response of the critical dovetail joint parts}

The critical parts of the dovetail joints are the lower parts LP1 and LP2. They belong to a group of notched structural elements. At the first step, the linear stress response will be obtained (the case of ideal elasticity). This stress response will serve to identify critical points in those lower parts (points with maximum values of principal stresses $\sigma_{1}$ ). After that, the values of corresponding nominal stresses $\sigma_{n}$ and theoretical stress concentration factors $K_{t}$ will be determined. In the end, the values of $\sigma_{n}$ and $K_{t}$ will be used for the computation of nonlinear stress-strain response (the case of elasto-plasticity).

Taking into account the steels selected, S1 and S2 will be added to the basic marks LP1 and LP2 of the lower parts, practically performing the task with four lower parts: LP1S1, LP1S2, LP2S1 and LP2S2.

Linear stress response. For the purpose of the linear stress response computation of the lower parts LP1 and LP2, the computational models were formed, as shown in Fig. 8.
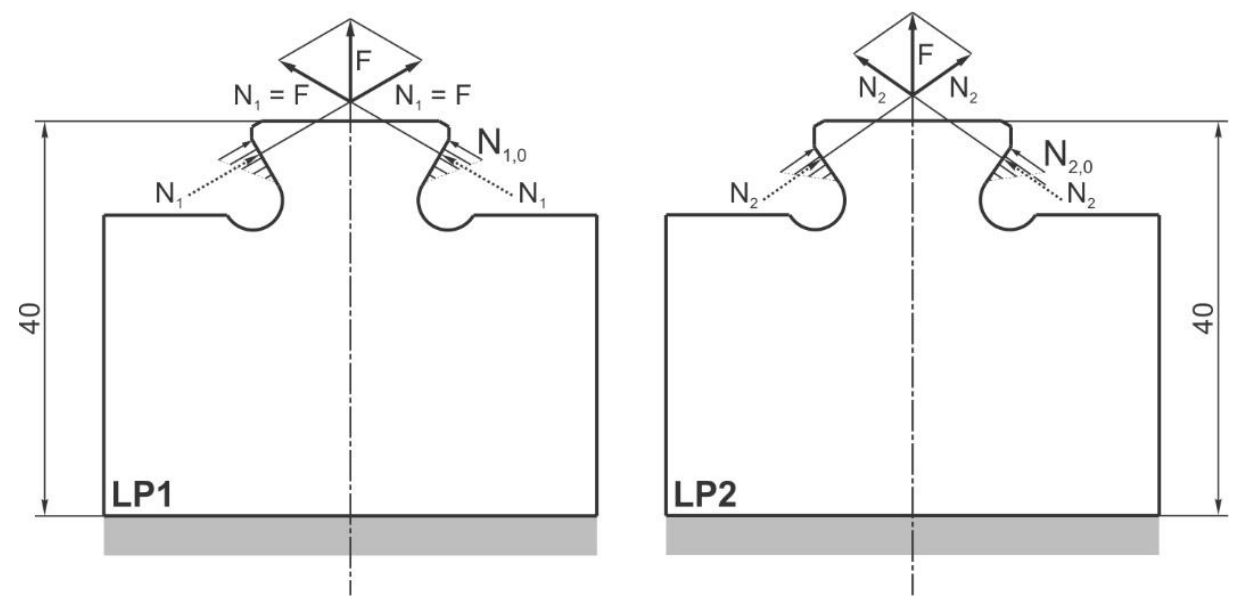

Fig. 8. Computational models of the lower parts LP1 and LP2

The influence of the upper parts UP1 and UP2, as can be seen in the previous figure, was compensated by distributing normal forces $N_{1}$ and $N_{2}$ along the contact lines. The values of these normal forces can be obtained using the following expressions: 


$$
\begin{aligned}
& N_{1}=\frac{F}{2 \cos 60^{\circ}} \\
& N_{2}=\frac{F}{2 \cos 55^{\circ}}
\end{aligned}
$$

In both cases, the force $F$ is the resultant of the normal forces $N_{1}$ and $N_{2}$.

After establishing the computational models shown in Fig. 8, using the finite element method (FEM) implemented in IDEAS Master Series 7 Software, FEM models of the lower parts LP1S1 and LP2S1 were generated (Fig. 9). The "plane stress parabolic" 8-noded finite element was used for discretization. For the generation of FEM models, the symmetry of given lower parts was used.
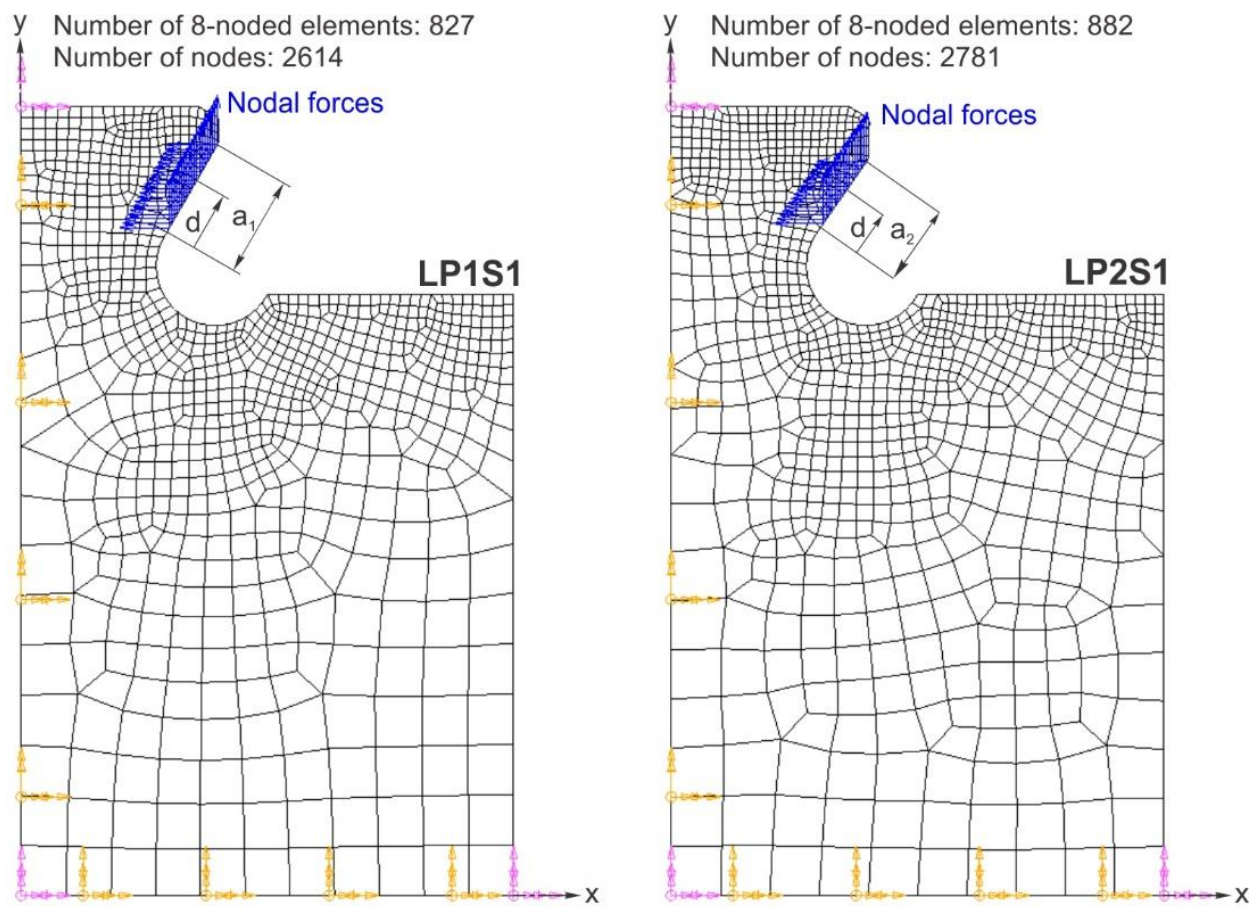

Fig. 9. FEM models of the lower parts LP1S1 and LP2S1

To all finite elements modulus elasticity $E=2.291846 \times 10^{8} \mathrm{mN} / \mathrm{mm}^{2}$, Poisson's coefficient $v=0.29$, shear modulus $G=8.883124 \times 10^{7} \mathrm{mN} / \mathrm{mm}^{2}$ and mass density $\rho=7.82 \times 10^{-6} \mathrm{~kg} / \mathrm{mm}^{3}$ (for steel $13 \mathrm{H} 11 \mathrm{~N} 2 \mathrm{~V} 2 \mathrm{MF}$, steel S1), were assigned. All finite elements were assigned the thickness of $10 \mathrm{~mm}$ as a physical property.

Boundary conditions connected with the FEM models of the observed lower parts are zero displacements for all nodes that belong to the $x$-axis, free vertical displacements for all nodes that belong to the $y$-axis (excluding node in the coordinate system origin), plus horizontal and vertical nodal forces.

The law of distribution of horizontal and vertical nodal forces is defined by the following expressions: 


$$
\begin{array}{ll}
H_{1}(d)=-\frac{N_{1,0}}{a_{1}} d \sin 60^{\circ}, & V_{1}(d)=\frac{N_{1,0}}{a_{1}} d \cos 60^{\circ} \\
H_{2}(d)=-\frac{N_{2,0}}{a_{1}} d \sin 55^{\circ}, & V_{2}(d)=\frac{N_{2,0}}{a_{1}} d \cos 55^{\circ}
\end{array}
$$

In these expressions the following can be noticed: normal nodal forces $N_{1,0}$ and $N_{2,0}$ at the end of contact lines, the lengths of contact lines $a_{1}$ and $a_{2}$ and $d$ as distances of a certain nod from the nod at the start of contact lines. The forces $N_{1,0}=4 \times 10^{6} \mathrm{mN}$ and $N_{2,0}=4.307 \times 10^{6} \mathrm{mN}$, correspond to the normal forces $N_{1}=42 \times 10^{6} \mathrm{mN}$ and $N_{2}=36.612 \times 10^{6} \mathrm{mN}$ when $F=42 \times 10^{6} \mathrm{mN}$ (see Fig. 8). The lengths of contact lines amount to: $a_{1}=5.079 \mathrm{~mm}$ and $a_{2}=4.074 \mathrm{~mm}$.

The isolines of principal stresses $\sigma_{1}$ in the segments of lower parts LP1S1 and LP2S1, with identified maximum stress values in the critical points $\mathrm{P}_{1}$ and $\mathrm{P}_{2}$, are shown in Fig.10.
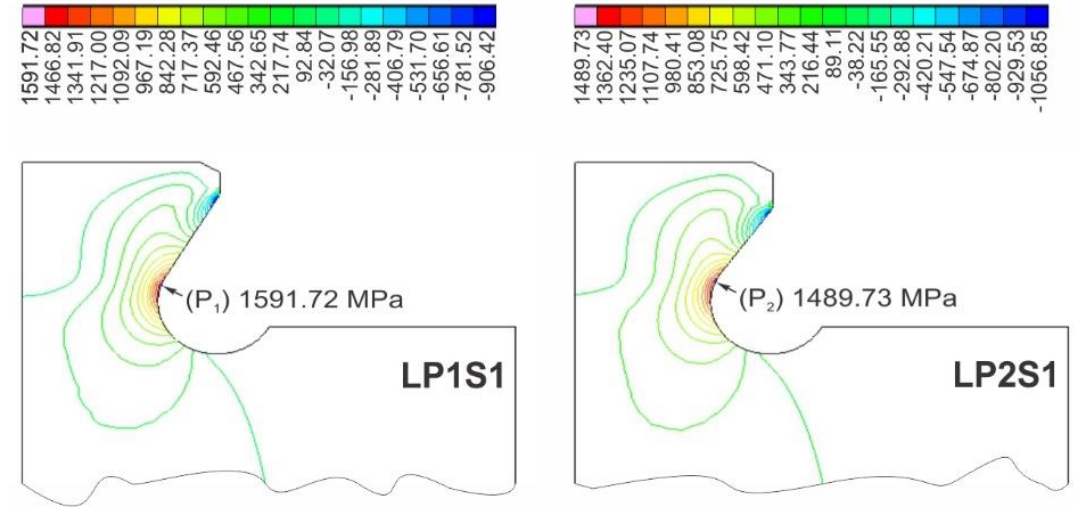

Fig. 10. The isolines of principal stresses $\sigma_{1}$ in the segments of lower parts LP1S1 and LP2S1, with identified maximum stress values in the critical points $\mathrm{P}_{1}$ and $\mathrm{P}_{2}$

The critical points $\mathrm{P}_{1}$ and $\mathrm{P}_{2}$ with stresses $\sigma_{1}\left(\mathrm{P}_{1}\right)=1591.72 \mathrm{MPa}$ and $\sigma_{1}\left(\mathrm{P}_{2}\right)=1489.73 \mathrm{MPa}$, belong to critical sections with areas $A_{1}=140.5 \mathrm{~mm}^{2}$ and $A_{2}=142.2 \mathrm{~mm}^{2}$. By dividing the force $\mathrm{F}=42 \times 10^{3} \mathrm{~N}$, with these areas, nominal stresses were obtained, i.e. $\sigma_{n 1}=298.932 \mathrm{MPa}$ (for the lower part LP1) and $\sigma_{n 2}=295.359 \mathrm{MPa}$ (for the lower part LP2).

Theoretical (or geometrical) stress concentration factors $K_{t 1}=5.325$ (for the lower part LP1) and $K_{t 2}=5.044$ (for the lower part LP2) were computed by dividing stresses $\sigma_{1}\left(\mathrm{P}_{1}\right)$ and $\sigma_{1}\left(\mathrm{P}_{2}\right)$ with the above mentioned nominal stresses.

Note that the same maps of the principal stresses $\sigma_{1}$ that are shown in Fig. 10 can also be obtained for the lower parts LP1S2 and LP2S2.

The data about linear stress response in the critical points that belong to the critical sections of all lower parts, at the level of nominal stresses, are included in Table 2. 


\begin{tabular}{|c|c|c|c|c|c|}
\hline $\begin{array}{l}\text { Lower } \\
\text { part }\end{array}$ & $\begin{array}{l}\text { Load } \\
\text { history }\end{array}$ & $\mathrm{k}$ & $\begin{array}{c}\text { Force cycle } \\
\mathrm{F}_{\mathrm{k}, \mathrm{u}}-\mathrm{F}_{\mathrm{k}, \mathrm{l}}-\mathrm{F}_{\mathrm{k}, \mathrm{u}}[\mathrm{kN}]\end{array}$ & $\begin{array}{l}\text { Nominal stress cycle } \\
\sigma_{\mathrm{nk}, \mathrm{u}}-\sigma_{\mathrm{nk}, \mathrm{l}}-\sigma_{\mathrm{nk}, \mathrm{u}}[\mathrm{MPa}]\end{array}$ & $\begin{array}{c}\text { Nominal stress range } \\
\Delta \sigma_{\mathrm{nk}}[\mathrm{MPa}]\end{array}$ \\
\hline \multirow{4}{*}{ LP1S1 } & \multirow{2}{*}{ LH1 } & 1 & $50-0-50$ & $355.871-0-355.871$ & 355.871 \\
\hline & & 2 & $42-5-42$ & $298.932-35.587-298.932$ & 263.345 \\
\hline & \multirow{2}{*}{ LH2 } & 3 & $55-0-55$ & $391.459-0-391.459$ & 391.459 \\
\hline & & 4 & $42-5-42$ & 298.932-35.587-298.932 & 263.345 \\
\hline \multirow{4}{*}{ LP2S1 } & \multirow{2}{*}{ LH1 } & 5 & $50-0-50$ & $351.618-0-351.618$ & 351.618 \\
\hline & & 6 & $42-5-42$ & 295.359-35.162-295.359 & 260.197 \\
\hline & \multirow{2}{*}{ LH2 } & 7 & $55-0-55$ & $386.780-0-386.780$ & 386.780 \\
\hline & & 8 & $42-5-42$ & $295.359-35.162-295.359$ & 260.197 \\
\hline \multirow{4}{*}{ LP1S2 } & \multirow{2}{*}{ LH1 } & 9 & $50-0-50$ & $355.871-0-355.871$ & 355.871 \\
\hline & & 10 & $42-5-42$ & $298.932-35.587-298.932$ & 263.345 \\
\hline & \multirow{2}{*}{ LH2 } & 11 & $55-0-55$ & 391.459-0-391.459 & 391.459 \\
\hline & & 12 & $42-5-42$ & $298.932-35.587-298.932$ & 263.345 \\
\hline \multirow{4}{*}{ LP2S2 } & \multirow{2}{*}{ LH1 } & 13 & $50-0-50$ & $351.618-0-351.618$ & 351.618 \\
\hline & & 14 & $42-5-42$ & $295.359-35.162-295.359$ & 260.197 \\
\hline & \multirow{2}{*}{ LH2 } & 15 & $55-0-55$ & $386.780-0-386.780$ & 386.780 \\
\hline & & 16 & $42-5-42$ & $295.359-35.162-295.359$ & 260.197 \\
\hline
\end{tabular}

Table 2. The data about linear stress response in the critical points that belong to the critical sections of all lower parts, at the level of nominal stresses

The values of already obtained nominal stress $\sigma_{n 1}=298.932 \mathrm{MPa}$ and $\sigma_{n 2}=295.359 \mathrm{MPa}$ are shown in Table 2. The first nominal stress is equal to the upper nominal stresses $\sigma_{n k, u}(k=$ $2,4,10,12)$ in the nominal stress cycles, while the second is also equal to the upper nominal stresses $\sigma_{n k, u}(k=6,8,14,16)$ in the nominal stress cycles.

The other upper and lower nominal stresses in the nominal stress cycles were obtained by multiplying values of the mentioned nominal stresses with the quotient of corresponding force in the force cycles and force that amounts to $42 \mathrm{kN}$. The ranges of nominal stresses $\Delta \sigma_{n k}$ were obtained as difference of the upper $\sigma_{n k, u}$ and the lower $\sigma_{n k, l}$ nominal stresses values in the nominal stress cycles.

Local nonlinear stress-strain response. Local nonlinear stress-strain response of our lower parts refers to their critical points. Such a stress-strain response was determined by stabilized hysteresis loops (two stabilized hysteresis loops per load history).

The $\mathrm{k}^{\text {th }}$ upper point $\left[(\Delta \varepsilon / 2)_{\mathrm{k}},(\Delta \sigma / 2)_{\mathrm{k}}\right]$ of the $\mathrm{k}^{\text {th }}$ main stabilized hysteresis loop that corresponds to the force cycles $50-0-50 \mathrm{kN}$ in the load history LH1 and 55-0-55 kN in the load history LH2 was determined by solving the system of equations

$$
\begin{aligned}
& \frac{\Delta \varepsilon}{2}=\frac{1}{2} \frac{K_{t i} \sigma_{n k, u}}{E_{j}}\left(\frac{K_{t i} \sigma_{n k, u}}{\frac{\Delta \sigma}{2} E_{j}}+1\right) \\
& \frac{\Delta \varepsilon}{2}=\frac{1}{E_{j}}\left(\frac{\Delta \sigma}{2}\right)+\left[\frac{1}{K^{\prime}{ }_{j}}\left(\frac{\Delta \sigma}{2}\right)\right]^{\frac{1}{n^{\prime}}}
\end{aligned}
$$


in which the indexes $i, j$ and $k$ had these values: $(i=1, j=1, k=1,3),(i=2, j=1, k=5,7)$, $(i=1, j=2, k=9,11)$ and $(i=2, j=2, k=13,15)$.

By solving the system of equations

$$
\begin{aligned}
& \Delta \varepsilon=\frac{1}{2} \frac{K_{t i} \Delta \sigma_{n k}}{E_{j}}\left(\frac{K_{t i} \Delta \sigma_{n k}}{\Delta \sigma E_{j}}+1\right) \\
& \Delta \varepsilon=\frac{1}{E_{j}}(\Delta \sigma)+2\left[\frac{1}{K_{j}^{\prime}}\left(\frac{\Delta \sigma}{2}\right)\right]^{\frac{1}{n_{j}^{\prime}}}
\end{aligned}
$$

the dimension $\Delta \varepsilon_{k} \times \Delta \sigma$ of $\mathrm{k}^{\text {th }}$ stabilized hysteresis loop was obtained.

The indexes $i, j$ and $k$ in (5) had these values: $(i=1, j=1, k=1,2,3,4),(i=2, j=1, k=$ $5,6,7,8),(i=1, j=2, k=9,10,11,12)$ and $(i=2, j=2, k=13,14,15,16)$.

The upper points, of the stabilized hysteresis loops that correspond to the force cycles 42-5$42 \mathrm{kN}$ belong to the main stabilized hysteresis loops. Their position, at the height $\Delta \sigma=\Delta \sigma^{\prime}$, measured from the lower point of the main hysteresis loops, was obtained by introducing auxiliary 42-0-42 kN force cycle and by solving the system equations (5) for the cases when are: $(i=1, j$ $=1, k=2,4),(i=2, j=1, k=6,8),(i=1, j=2, k=10,12)$ and $(i=2, j=2, k=14,16)$.

The first equations in the systems (4) and (5) are two forms of Birger-Sonsino's curve (Birger, 1985 and Sisino, 1993). The second equations in that systems are equations of the cyclic stress-strain curve and Massing's curve (for steel S1 if $j=1$ and steel S2 if $j=2$ ). These curves are broadly described by Bannatine, Comer and Handrock (1990).

The stress concentration factors $K_{t i}(i=1,2)$ in Birger-Sonsino's curves had values of already determined stress concentration factors $K_{t 1}=5.325$ and $K_{t 2}=5.044$.

The values for $E_{j}, K_{j}^{\prime}$ and $n_{j}^{\prime}(j=1,2)$ in the systems of equations (4) and (5) were taken from Table 1. Index $j=1$ refers to steel $13 \mathrm{H} 11 \mathrm{~N} 2 \mathrm{~V} 2 \mathrm{MF}$ (steel S1), while index $j=2$ refers to steel AISI 304 (steel S2). The corresponding values of upper nominal stresses $\sigma_{n k, u}$ in nominal stress cycles, including stress ranges $\Delta \sigma_{n k}$, were taken from Table 2 .

The systems of equations (4) and (5) were solved graphically in DRAFTING modulus of IDEAS Master Series 7 Software by Posavljak (2008). By the special programs generated in Visual FORTRAN, all curves were copied to corresponding spline curves.

Two examples of graphically determined nonlinear stress-strain responses in the critical points of the lower parts LP1S1 and LP1S2 exposed to load history LH1 are presented in Fig. 11 and Fig. 12.

Considering the strain memory of metals, the stabilized hysteresis loops (two per load history) were modelled using Massing's curve for steel S1 and steel S2. 


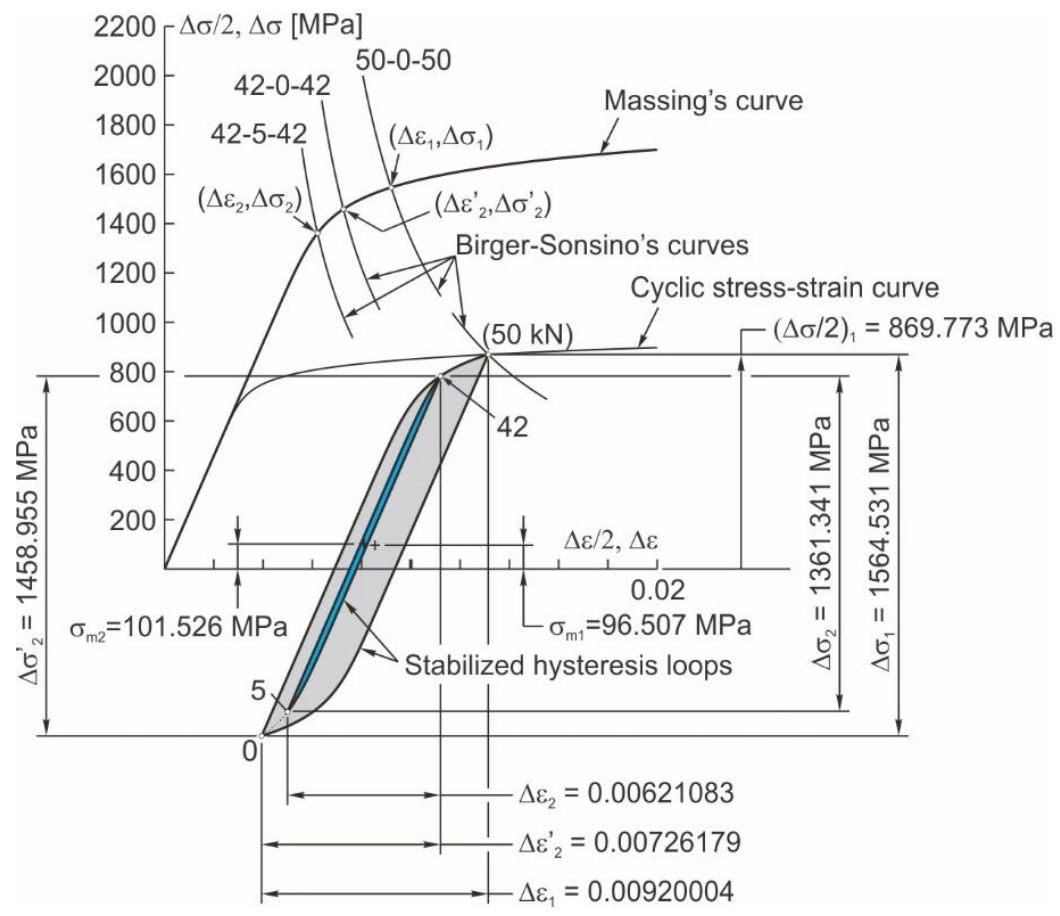

Fig. 11. Nonlinear stress-strain response in the critical point of the lower part LP1S1 exposed to the load history LH1

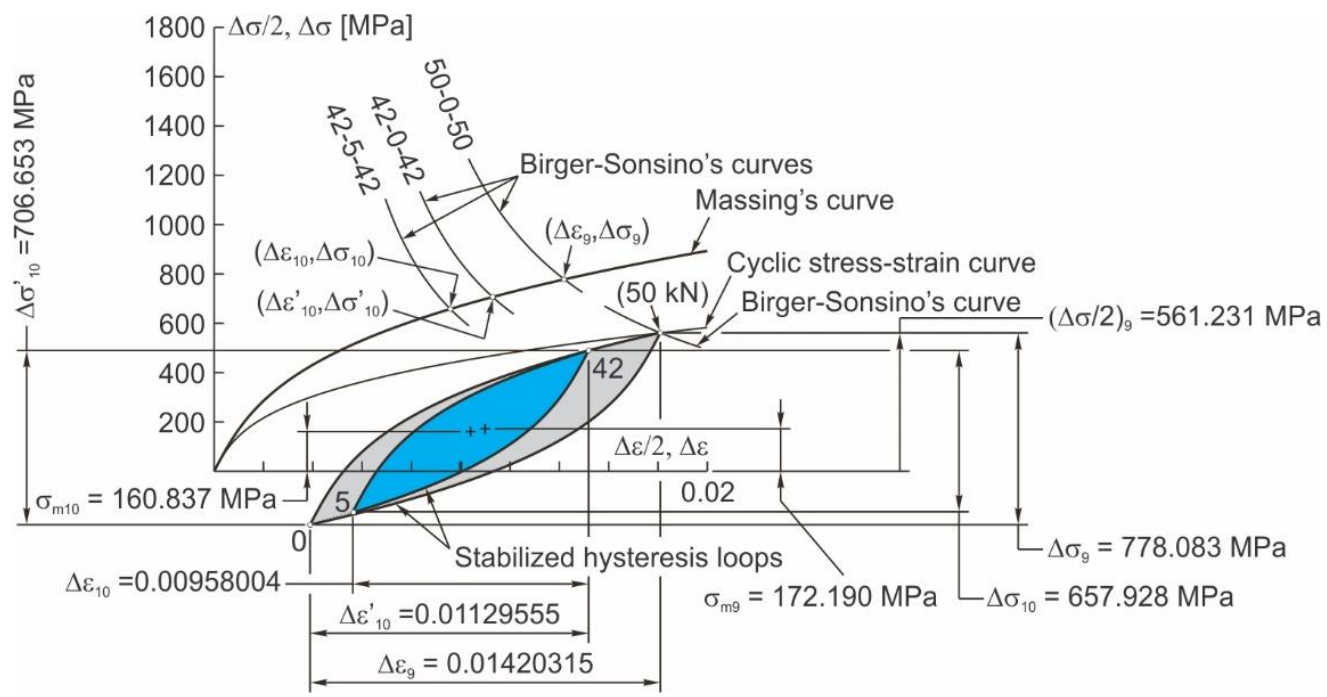

Fig. 12. Nonlinear stress-strain response in the critical point of the lower part LP1S2 exposed to the load history LH1

The set of numerical data on the nonlinear stress-strain response in the critical points of all lower parts exposed to load histories LH1 and LH2 is shown in Table 3. 


\begin{tabular}{|c|c|c|c|c|c|c|c|}
\hline $\begin{array}{l}\text { Lower } \\
\text { part }\end{array}$ & $\begin{array}{l}\text { Load } \\
\text { history }\end{array}$ & $\mathrm{k}$ & $\begin{array}{c}\text { Force cycle } \\
\mathrm{F}_{\mathrm{k}, \mathrm{u}}-\mathrm{F}_{\mathrm{k}, \mathrm{l}}-\mathrm{F}_{\mathrm{k}, \mathrm{u}} \\
{[\mathrm{kN}]}\end{array}$ & $\begin{array}{c}\text { Mean stress } \\
\sigma_{\mathrm{mk}}[\mathrm{MPa}]\end{array}$ & $\begin{array}{c}\text { Strain range } \\
\qquad \Delta \varepsilon_{\mathrm{k}}\end{array}$ & $\begin{array}{c}\text { Stress range } \\
\Delta \sigma_{\mathrm{k}}[\mathrm{MPa}]\end{array}$ & $\begin{array}{c}(\Delta \sigma / 2)_{\mathrm{k}} \\
{[\mathrm{MPa}]}\end{array}$ \\
\hline \multirow{4}{*}{ LP1S1 } & \multirow{2}{*}{ LH1 } & 1 & $50-0-50$ & 96.507 & 0.00920004 & 1564.531 & 869.773 \\
\hline & & 2 & $42-5-42$ & 101.526 & 0.00621083 & 1361.341 & --- \\
\hline & \multirow{2}{*}{ LH2 } & 3 & $55-0-55$ & 89.076 & 0.01053913 & 1582.203 & 880.177 \\
\hline & & 4 & $42-5-42$ & 76.259 & 0.00621083 & 1361.341 & --- \\
\hline \multirow{4}{*}{ LP2S1 } & \multirow{2}{*}{ LH1 } & 5 & $50-0-50$ & 103.575 & 0.00839119 & 1517.593 & 862.372 \\
\hline & & 6 & $42-5-42$ & 109.980 & 0.00576499 & 1259.030 & \\
\hline & \multirow{2}{*}{ LH2 } & 7 & $55-0-55$ & 93.948 & \begin{tabular}{|l|}
0.00958561 \\
\end{tabular} & 1558.052 & 872.974 \\
\hline & & 8 & $42-5-42$ & 80.123 & 0.00576499 & 1295.030 & --- \\
\hline \multirow{4}{*}{ LP1S2 } & \multirow{2}{*}{ LH1 } & 9 & $50-0-50$ & 172.190 & 0.01420315 & 778.083 & 561.231 \\
\hline & & 10 & $42-5-42$ & 160.837 & 0.00958004 & 657.928 & --- \\
\hline & \multirow{2}{*}{ LH2 } & 11 & $55-0-55$ & 179.668 & 0.01611625 & 819.441 & 589.389 \\
\hline & & 12 & $42-5-42$ & 147.636 & 0.00958004 & 657.928 & --- \\
\hline \multirow{4}{*}{ LP2S2 } & \multirow{2}{*}{ LH1 } & 13 & $50-0-50$ & 167.213 & 0.01301527 & 750.323 & 542.374 \\
\hline & & 14 & $42-5-42$ & 156.184 & 0.00879543 & 633.470 & \\
\hline & \multirow{2}{*}{ LH2 } & 15 & $55-0-55$ & 174.431 & \begin{tabular}{|l|}
0.01476007 \\
\end{tabular} & 790.519 & 569.690 \\
\hline & & 16 & $42-5-42$ & 143.304 & 0.00879543 & 633.470 & $\begin{array}{ll}-- \\
-1\end{array}$ \\
\hline
\end{tabular}

Table 3. The set of numerical data on the nonlinear stress-strain response in the critical points of all lower parts exposed to the load histories LH1 and B2

\subsection{Damages and crack initiation life estimation}

Damages and crack initiation life estimation here was based on Palmgren-Miner's rule developed by Palmgren (1924) and Miner (1945).

Damages estimation. The $\mathrm{k}^{\text {th }}$ damage $D_{k}$ of all lower parts, provoked by $\mathrm{k}^{\text {th }}$ force cycle in the load histories LH1 and LH2, was computed using the expression

$$
D_{k}=\frac{N_{k}}{N_{f k}}, \quad k=1,2, \ldots, 16
$$

in which $N_{k}=1$ represents the number of $\mathrm{k}^{\text {th }}$ force cycles in the load histories LH1 and LH2, while $N_{f k}$ represents the number of accumulated $\mathrm{k}^{\text {th }}$ force cycles to crack initiation (to failure) in the certain lower part of our dovetail joints.

The set of $N_{f}=N_{f k}$ data was obtained by solving the system of equations

$$
\begin{aligned}
\frac{\Delta \varepsilon}{2} & =\frac{\sigma_{f, j}^{\prime}-\sigma_{m k}}{E_{j}} N_{f}^{b_{j}}+\varepsilon_{f, j}^{\prime} N_{f}^{c_{j}} \\
\frac{\Delta \varepsilon}{2} & =\frac{\Delta \varepsilon_{k}}{2}
\end{aligned}
$$

in which the indexes $j$ and $k$ had the next values: $(j=1, k=1,2,3,4,5,6,7,8)$ and $(j=2, \mathrm{k}=$ $9,10,11,12,13,14,15,16)$. The values of $\mathrm{k}^{\text {th }}$ mean stresses $\sigma_{m k}$ and $\mathrm{k}^{\text {th }}$ strain range $\Delta \varepsilon_{k}$ in that system were taken from Table 3 .

The first equation in the system (7) is the equation of Morrow's strain-life curve of steel S1 if $j=1$ and steel S2 if $j=2$. This curve, suggested by Morrow (1968) and applied by Bannantine, Comer an Handrock (1990), represents one of the modifications of the basic strain-life curve. 
Posavljak (2008) and after that Maksimovic, Posavljak and other (2011) has shown that by using Morrow's curves in combination with Birger-Sonsino's curves, satisfying results of crack initiation life estimation can be obtained in comparison with experimental results.

The system of equations (7) was also solved graphically. The set of Morrow's curves was copied to the corresponding set of spline curves.

The data about $N_{k}, N_{f}=N_{f k}$, and $D_{k}$ that refer to all observed lower parts exposed to the load histories LH1 and LH2 are shown in Table 4. The example of graphical determined accumulated numbers of force cycles 50-0-50 in the load history LH1 ( $N_{f 1}$ and $N_{f 9}$ in Table 4$)$ to the crack initiation in the lower parts LP1S1 and LP1S2 is shown in Fig. 13.

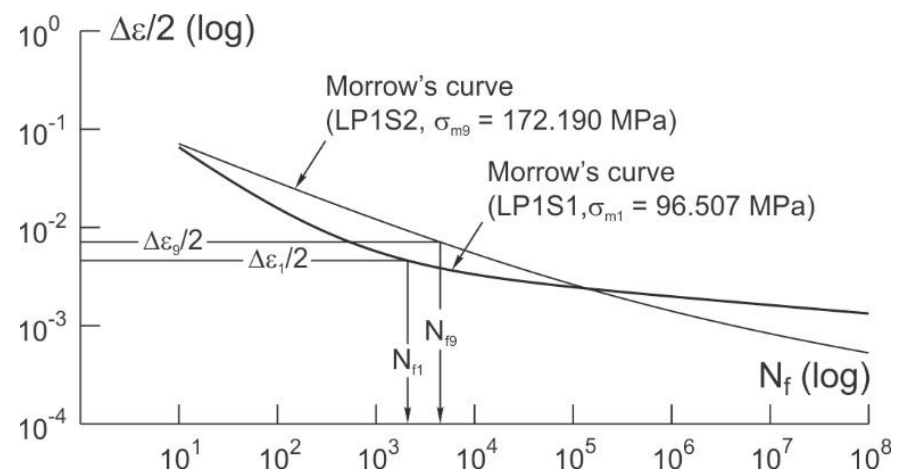

Fig. 13. Example of graphical determined accumulated numbers of force cycles 50-0-50 in the load history LH1 $\left(N_{f 1}\right.$ and $\left.N_{f 9}\right)$ to crack initiation in the lower parts LP1S1 and LP1S2

\begin{tabular}{|c|c|c|c|c|c|c|}
\hline Lower parts & $\begin{array}{c}\text { Load } \\
\text { history }\end{array}$ & $\mathrm{k}$ & $\begin{array}{c}\text { Force cycle } \\
\mathrm{F}_{\mathrm{k}, \mathrm{u}}-\mathrm{F}_{\mathrm{k}, \mathrm{l}}-\mathrm{F}_{\mathrm{k}, \mathrm{u}}[\mathrm{kN}]\end{array}$ & $\mathrm{N}_{\mathrm{k}}$ & $\mathrm{N}_{\mathrm{fk}}$ & $\begin{array}{c}\text { Damage } \\
\mathrm{D}_{\mathrm{k}}=\mathrm{N}_{\mathrm{k}} / \mathrm{N}_{\mathrm{fk}}\end{array}$ \\
\hline \multirow{4}{*}{ LP1S1 } & \multirow{2}{*}{ LH1 } & 1 & $50-0-50$ & 1 & 2096 & 0.00047710 \\
\hline & & 2 & $42-5-42$ & 1 & 15175 & 0.00006590 \\
\hline & \multirow{2}{*}{ LH2 } & 3 & $55-0-55$ & 1 & 1309 & 0.00076394 \\
\hline & & 4 & $42-5-42$ & 1 & 16889 & 0.00005921 \\
\hline \multirow{4}{*}{ LP2S1 } & \multirow{2}{*}{ LH1 } & 5 & $50-0-50$ & 1 & 2995 & 0.00033389 \\
\hline & & 6 & $42-5-42$ & 1 & 24894 & 0.00004017 \\
\hline & \multirow{2}{*}{ LH2 } & 7 & $55-0-55$ & 1 & 1806 & 0.00055371 \\
\hline & & 8 & $42-5-42$ & 1 & 28812 & 0.00003471 \\
\hline \multirow{4}{*}{ LP1S2 } & \multirow{2}{*}{ LH1 } & 9 & $50-0-50$ & 1 & 4482 & 0.00022311 \\
\hline & & 10 & $42-5-42$ & 1 & 14588 & 0.00006855 \\
\hline & \multirow{2}{*}{ LH2 } & 11 & $55-0-55$ & 1 & 3103 & 0.00032227 \\
\hline & & 12 & $42-5-42$ & 1 & 14762 & 0.00006774 \\
\hline \multirow{4}{*}{ LP2S2 } & \multirow{2}{*}{ LH1 } & 13 & $50-0-50$ & 1 & 5800 & 0.00017241 \\
\hline & & 14 & $42-5-42$ & 1 & 19069 & 0.00005244 \\
\hline & \multirow{2}{*}{ LH2 } & 15 & $55-0-55$ & 1 & 4005 & 0.00024969 \\
\hline & & 16 & $42-5-42$ & 1 & 19304 & 0.00005180 \\
\hline
\end{tabular}

Table 4. $\mathrm{N}_{\mathrm{k}}, \mathrm{N}_{\mathrm{fk}}$ and $\mathrm{D}_{\mathrm{k}}$ data for all lower parts exposed to the load histories LH1 and LH2 
Using the data about damages $D_{k}$ contained in Table 4 , damages $D_{k, k+1}$ for all lower parts, caused by the load histories LH1 and LH2, were obtained. For that purpose, we used the expression

$$
D_{k, k+1}=D_{k}+D_{k+1}, \quad k=1,3,5,7,9,11,13,15 .
$$

Crack initiation life estimation. The results of crack initiation life (CIL) estimation of all lower parts exposed to the load histories LH1 and LH2 were obtained using the expression

$$
C I L_{k, k+1}=0.5 \times \frac{1}{D_{k, k+1}}, \quad k=1,3,5,7,9,11,13,15 .
$$

The results of estimated damages and estimated crack initiation life of all observed lower parts in the case of exposition to the load histories LH1 and LH2 are shown in Table 5.

\begin{tabular}{|c|c|c|c|c|c|}
\hline \multirow{2}{*}{ Lower part } & \multirow{2}{*}{$\begin{array}{c}\text { Load } \\
\text { history }\end{array}$} & \multicolumn{2}{|c|}{ Damage caused by load history } & \multicolumn{2}{c|}{ CIL [Hours] } \\
\cline { 2 - 6 } & Mark & Value & Mark & Value \\
\hline \multirow{2}{*}{ LP1S1 } & LH1 & $\mathrm{D}_{1,2}$ & 0.00054300 & CIL $_{1,2}$ & 920.5 \\
\cline { 2 - 6 } & LH2 & $\mathrm{D}_{3,4}$ & 0.00082315 & CIL $_{3,4}$ & 607 \\
\hline \multirow{2}{*}{ LP1S2 } & LH1 & $\mathrm{D}_{5,6}$ & 0.00029166 & CIL $_{5,6}$ & 1714 \\
\cline { 2 - 6 } & LH2 & $\mathrm{D}_{7,8}$ & 0.00039001 & CIL $_{7,8}$ & 1282 \\
\hline \multirow{2}{*}{ LP2S1 } & LH1 & $\mathrm{D}_{9,10}$ & 0.00037406 & CIL $_{9,10}$ & 1336.5 \\
\cline { 2 - 6 } & LH2 & $\mathrm{D}_{11,12}$ & 0.00058842 & $\mathrm{CIL}_{11,12}$ & 849.5 \\
\hline \multirow{2}{*}{ LP2S2 } & LH1 & $\mathrm{D}_{13,14}$ & 0.00022485 & $\mathrm{CIL}_{13,14}$ & 2223.5 \\
\cline { 2 - 6 } & LH2 & $\mathrm{D}_{15,16}$ & 0.00030149 & $\mathrm{CIL}_{15,16}$ & 1658 \\
\hline
\end{tabular}

Table 5. The results of estimated damages and estimated crack initiation life (CIL) of all observed lower parts in the case of exposition to the load histories LH1 and LH2

\section{Results comparison of crack initiation life estimation}

The results comparison of crack initiation life estimation, of the lower parts LP1S1, LP2S1, LP1S2 and LP2S2, here are presented by corresponding histograms.

The overload of $10 \%$ covered by the load history LH2, in the same lower parts of our dovetail joints, causes a significant drop of crack initiation life (Fig. 14). For LP1S1 34.06\%, for LP1S2 $25.20 \%$, for LP2S1 $36.44 \%$ and for LP2S $25.43 \%$.

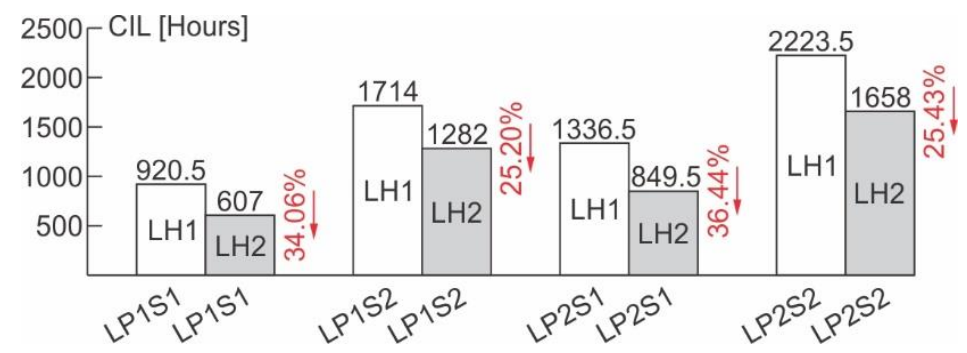

Fig. 14. Histogram of crack initiation life (CIL) comparison of the same lower parts exposed to the load histories LH1 and LH2 
CIL of the lower parts LP1S2 and LP2S2, in comparison to CIL of the lower LP1S1 and LP2S1, for the case of exposure to the same load histories, is significantly higher (Fig. 15). The AISI 304 steel (S2 steel) with cyclic properties is prevailing.

Practically, the lower part LP1S2 has $86.20 \%$ greater CIL than the lower part LP1S1 in the case of exposure to load histories LH1, and $111.20 \%$ greater in the case of exposure to load histories LH2.

The lower part LP2S2 has $66.37 \%$ greater CIL than the lower part LP2S1 in the case of exposure to load histories LH1, and $95.17 \%$ greater in the case of exposure to load histories LH2.

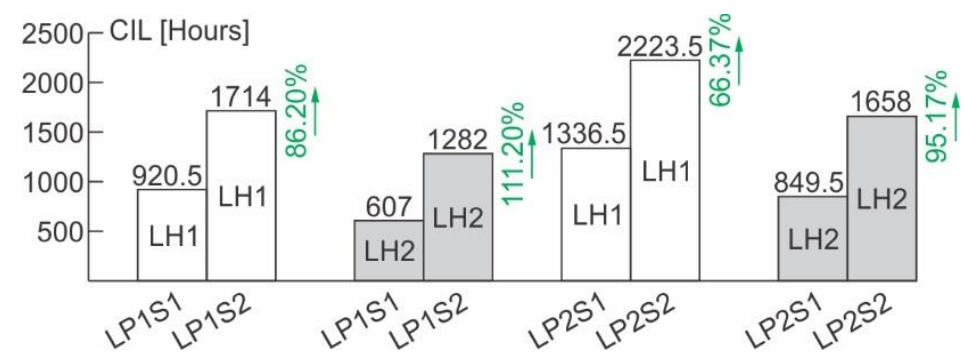

Fig. 15. Histogram of crack initiation life (CIL) comparison of the lower parts LP1S1, LP1S2, LP2S1 and LP2S2 exposed to the load histories LH1 and LH2

CIL of the lower parts LP2S1 and LP2S2 in comparison with CIL of the lower parts LP1S1 and LP1S2, for the case of exposure to the same load histories, has also increased (Fig. 16). The increase is a consequence of flank angle change from $60^{\circ}$ to $55^{\circ}$.

The lower part LP2S1 has $45.15 \%$ greater CIL than the lower part LP1S1 in the case to exposure to load histories LH1, and 39.95\% greater in the case of exposure to load histories LH2.

The lower part LP2S2 has $29.73 \%$ greater CIL than the lower part LP1S1 in the case of exposure to load histories LH1, and $29.33 \%$ greater in the case of exposure to load histories LH2.

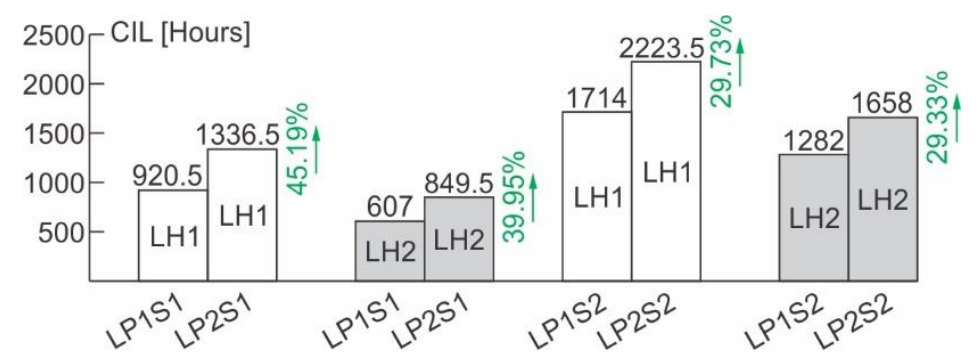

Fig. 16. Histogram of crack initiation life (CIL) comparison of the lower parts LP1S1, LP1S2, LP2S1 and LP2S2 exposed to the load histories LH1 and LH2

As can be seen in Fig. 17, the lower part LP2S2 has a distinctly greater CIL in comparison to the CIL of the lower part LP1S1, for the case of exposure to the same load histories. Here the flank angle change from $60^{\circ}$ to $55^{\circ}$, together with steel change, is dominant $(141.55 \%$ and $173.15 \%$, in favor of the lower part LP2S2). 


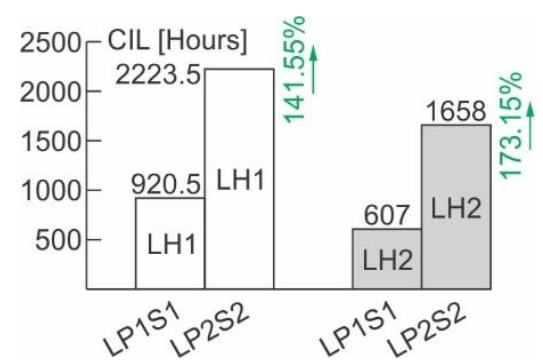

Fig. 17. Histogram of crack initiation life (CIL) comparison of the lower parts LP1S1, LP2S2 exposed to the load histories LH1 and LH2

\section{Conclusions}

On the basis of the above-presented results, the possibilities of crack initiation life extension of the first stage low pressure compressor disk of R25-300 jet engine have been discovered. The first possibility refers to the application of a flank angle of $55^{\circ}$ in its joints with blades, dovetail joints. That angle is better than the flank angle of $60^{\circ}$. The second possibility refers to AISI 304 steel that needs to be chosen because it has better resistance to low cycle fatigue than $13 \mathrm{H} 11 \mathrm{~N} 2 \mathrm{~V} 2 \mathrm{MF}$ steel in the defined heat treatment state. The best, third possibility combines the previous two possibilities.

Therefore, for the first stage low pressure compressor disk of R25-300 jet engine, the third version can be proposed. This version has been marked as disk D3, that would be made of AISI 304 steel and that would have dovetail grooves with newly-proposed transition rounding at the bottom and with the flank angles of $55^{\circ}$. The crack initiation life of disk D3 would be longer than crack initiation life of disk D2 that would be made of 13H11N2V2MF steel and would have dovetail grooves with newly-proposed rounding at the bottom and flank angles of $60^{\circ}$.

\section{References}

Bannantine J A, Comer J and Handrock J (1990). Fundamentals of Material Fatigue Analysis, Prentice-Hall, Englewood Cliffs, New Jersey.

Birger I A (1985). Prognozirovanie resursa pri malociklovoj ustalosti, Problemy prochnosti, No $10,39-44$.

Kostaes D (1994). Fatigue Behaviour and Analysis, Talat Lecture 2401, Technishe Universitat Munchen, European Aluminium Association - EAA.

Kozakievisz A, Grzejszczak O and Lacki T (2017). Numerical and Experimental Analysis of Compressor's Jet Engine Blade Joint Including the Model Parameterization, Mechanik, Vol. 90, No. 7, 562-564.

Maksimovic S, Posavljak S, Maksimovic K, Nikolic V, Djurkovic V (2011). Total Fatigue Life Estimation of Notched Structural Components Using Low-Cycle Fatigue Properties, Strain, Volume 47, Issue Supplement s2, 341-349.

Miner M A (1945). Cumulative Damage in Fatigue, Journal of Applied Mechanics, 76, A159164.

Morrow J (1968). Fatigue Design Handbook, Advances in Engineering, Vol. 4, Society of Automotive Engineers, Warrendale, Pa., Sec. 3.2, 21-29.

Palmgren A (1924). Die Lebensdauer von Kugellagern, Verfahenstechnik, Berlin, 68, 339-341 
Posavljak S (2008). Fatigue Life Investigation of Aero Engine Rotating Disks (in Serbian), Doctoral Dissertation, University of Belgrade, Faculty of Mechanical Engineering.

SAE J1099 (2002). Technical Report on Low Cycle Fatigue Properties Ferrous and Non-ferrous Materials, Society of Automotive Engineers, Inc.

Shlyannikov N, Yarulin R and Istyryakov S (2019). Failure Analysis of an Aircraft GTD Compressor Disk on the Base of Imitation Modeling Principles, Procedia Structural Integrity $18,322-329$.

Sonsino C M (1993). Zur Bewertung Schwingfestigkeitsverhaltens von Bauteilen mit Hilife Örtlicher Beanspruchungen, Konstrukcion, 45, 25-33.

Stepovoy S, Pribora I (2018). Analiz Evolyucii Konstrukcii Zamkovogo Soedineniya Rabochih Koles Kompressorov GTD, Vestnik dvigatelestroenija, No. 1, 53-59. 